\title{
The Role Of Usfulness In Mediation The Effect Of Arqument Quality And Popular Post In Social Media Marketing On Tendency To Give Like Symbol And Share The Content
}

\author{
Ita Prihatining Wilujeng ${ }^{1}$, Handri Dian Wahyudi ${ }^{2}$, Adela Shabrina Prameka ${ }^{3}$ \\ Management Departement, Universitas Negeri Malang \\ *Corresponding Author: \\ Email: ita.prihatining.fe@um.ac.id
}

\begin{abstract}
.
Easy access to the internet provides opportunities and makes it easier to carry out business functions. The use of social media is one of the important marketing tools, messages in social media can change user attitudes and trigger consumer interaction. This study looks at the effect of argument quality and posts popularity on consumer tendencies to like and share information on social media related to a product or service mediated by usefulness. The responses of 300 respondents were analysed using PLS, the results showed that argument quality and post popularity had an influence on giving like symbols and share intentions on their social media.
\end{abstract}

Keywords: Social media, argument quality, post popularity, usefulness, like intention, share intention.

\section{INTRODUCTION}

Internet use encourages online activities. People use online networking not only for communication and sharing information but also to support business processes. Through the Internet, companies can obtain various information and make some offers. For the consumer, the Internet is also helpful. They find some information and determine the products they want. Usually, consumers are more interested in browsing product features online before making some purchases (Ahmed \& Zahid, 2014). So the important thing for companies is to understand consumers and retain them. The ease of accessing the internet network provides many positive benefits in the company's communication process, one of which is using social media. The existence of social media comes up with opportunities as an essential marketing tool. Touching and persuasive messages delivered online can affect consumers' emotions and change their attitude to act and interact enthusiastically (Bhattacherjee \& Premkumar, 2004). Marketing through social media using social networks such as Instagram is an important marketing method today. These circumstances give opportunities company to share content, information and build relationships with consumers (Kim \& Ko, 2012).Companies see this as a good opportunity in their marketing strategy, so many companies take advantage of this phenomenon by making social media an opportunity to sell their products.

The fact the accessibility of social media can be accessed anytime and anywhere makes introducing and selling a product through social media can save marketing costs while the reach is broad. In addition, social media also provides extraordinary opportunities for customers to share and disseminate brand-related content and product usage information throughout the world (Ahmed \& Zahid, 2014). The character of social media that is able and easy to spread messages makes it a powerful communication tool. Thus, marketing managers should persuade Instagram users to share the content with relatives, colleagues, or friends. Therefore, effective information dissemination is an essential factor in the favourable result of social media marketing and compels Instagram users to facilitate promotional activities. This social media provides facilities to present the appearance of a product or service. It is also easy for anyone who wants to write comments on the product. So that potential customers can see reviews from other customers who have used the product first. According to 
Gautam \& Sharma, (2017), social media instruments help in mastery customers' internet usage patterns, looking for product information patterns, customer reviews about their experiences with products, consumer decisionmaking processes. This study explores how social media users are willing to forward messages and spread messages. This study investigates the characteristics of contents and how Internet user evaluations affect communicative intentions.

\section{LITERATURE REVIEW}

Electronic word of mouth (eWOM) is a form of marketing communication through Internet media containing positive or negative statements made by potential consumers, about a product and business, (HennigThurau, Gwinner, Walsh, \& Gremler, 2004). The existence of E-WOM hugely affects the marketing process in the present time, because the tendency to use social media as a marketing tool is quite popular today.In sorting and using information sourced from social media, it depends on the quality of the argument. Argument quality refers to the persuasive power of post content (Bhattacherjee \& Sanford, 2006) and is a significant factor in recipient perception that can lead to recipient attention (Coulter \& Punj, 2004). Strong arguments lead to favourable responses regarding posts. If a post is full of incorrect content, broken links, unrelated topics, and ads, the recipient may have a negative view. In addition, the popularity of posts also affects the number of likes and influences consumers to share and respond to comments on posts (De Vriesa et al., 2012), thus directly influencing usability and indirectly influencing consumer behavioural intentions in determining their decisions.

Therefore, post popularity directly affects preferences and indirectly affects behavioural intentions to choose available alternative options (Sinclair, Moore, Mark, Soldat, \& Lavis, 2010).Post acceptance is one of them influenced by usability. Usability refers to users' perceptions derived from personal or professional judgments about content that can benefit them in browsing posts (Bhattacherjee \& Sanford, 2006), receiver beliefs about the usefulness of posts influence preferences (Bhattacherjee \& Premkumar, 2004). Recipients express liking behavior and are willing to pass on information when interested in posts that match their expectations. Therefore, preferences positively affect eWOM intentions (Hsu \& Lin, 2008; Murray \& Haeubl, 2011). Likes have a positive meaning, some likes' intentions require a powerful connection to the post. Content that receives more likes will attract more attention and are more likely to be shared (Hinz, Skiera, Barrot, \& Becker, 2011). Therefore, liking to gather power positively influences sharing behavior (Cheung \& Thadani, 2012).

\section{METHOD}

This research deliver achieved the objectives, which were to prove the influence of independent variables on the dependent variable and to explain the existence of mediating variables as formulated in the hypothesis. This research design is a confirmatory study that aims to test the theory with a cross-sectional research time, the scope of the topic is statistical research, and the research environment is field research. Data to measure each research variable was collected using a questionnaire instrument. The research questionnaire containing question items describing the variables studied was given to 300 café/restaurant visitors on a smallmedium scale entrepreneur who used reviews on Instagram social media as a reference for decision making. In this study, The relationship between variables can be described as follows:

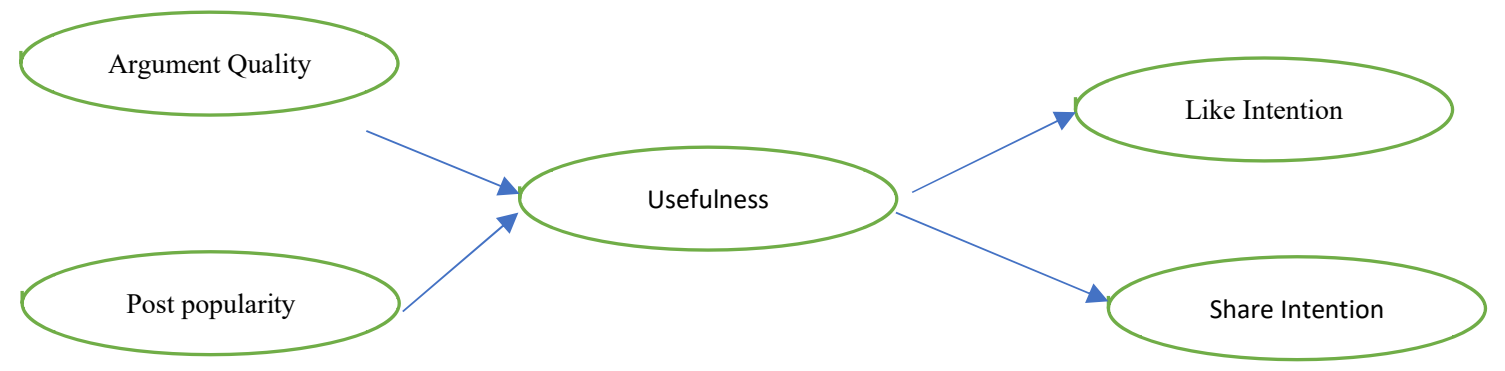

http://ijstm.inarah.co.id 


\section{DATA ANALYSIS AND RESULTS Descriptive Analysis}

The description of the variables studied is presented using the results of the frequency distribution of respondents' answers for each item. Each variable consists of several questions. The respondents' answers varied greatly, from strongly disagree to strongly agree. So, this description will show the proportion of neutral respond (not giving an opinion) and agree to and strongly agree to responses that respond positively in the sense of answering agree or strongly agree. The neutral answer describes the part of the respondent who does not have a strong belief in the direction of the questions.

\section{Argument Quality}

Argument quality consists of 3 items providing characteristics of how consumers give reasons for assessing quality. A detailed description of each item is described in the following table.

Table 1. Frequency Distribution of Answers on Argument Quality

\begin{tabular}{|c|c|c|c|c|c|c|c|c|c|c|c|}
\hline & \multicolumn{10}{|c|}{ Score } & \multirow{3}{*}{ Average } \\
\hline & \multicolumn{2}{|l|}{1} & \multicolumn{2}{|l|}{2} & \multicolumn{2}{|l|}{3} & \multicolumn{2}{|l|}{4} & \multicolumn{2}{|l|}{5} & \\
\hline & $\mathrm{f}$ & $\%$ & $\mathrm{f}$ & $\%$ & $\mathrm{f}$ & $\%$ & $\mathrm{f}$ & $\%$ & $\mathrm{f}$ & $\%$ & \\
\hline $\begin{array}{llll}\begin{array}{l}\text { Food review } \\
\text { informative }\end{array} & \text { post is } & \text { very } \\
\end{array}$ & 30 & 10.0 & 53 & 17.7 & 93 & 31.0 & 69 & 23.0 & 55 & 18.3 & 3.22 \\
\hline Food review post is very usefullfaat & 16 & 5.3 & 67 & 22.3 & 111 & 37.0 & 49 & 16.3 & 57 & 19.0 & 3.21 \\
\hline $\begin{array}{l}\text { Food review post is very helpful in } \\
\text { making decisions }\end{array}$ & 17 & 5.7 & 36 & 12.0 & 109 & 36.3 & 67 & 22.3 & 71 & 23.7 & 3.46 \\
\hline
\end{tabular}

The description of several reasons consumers judge quality has an average in the range of $3.21-3.46$ illustrate that consumers give varying degrees of agreement in the sense that there are consumers who take much consideration in posting reviews, meanwhile there are also those who respond very few thought. Posting food reviews is very helpful in making decisions, which are the things that are considered the most. On the contrary, a very useful food review statement is the lowest consideration.

\section{Post Popularity}

Post popularity consists of 3 items providing characteristics of how consumers give reasons for assessing the popularity of the product. A detailed description of each item is described in the following table:

Table 2. Frequency Distribution of Answers on Post Popularity

\begin{tabular}{|c|c|c|c|c|c|c|c|c|c|c|c|}
\hline & \multicolumn{10}{|c|}{ Score } & \multirow{3}{*}{ Average } \\
\hline & \multicolumn{2}{|l|}{1} & \multicolumn{2}{|l|}{2} & \multicolumn{2}{|l|}{3} & \multicolumn{2}{|l|}{4} & \multicolumn{2}{|l|}{5} & \\
\hline & $\mathrm{f}$ & $\%$ & $\mathrm{f}$ & $\%$ & $\mathrm{f}$ & $\%$ & $\mathrm{f}$ & $\%$ & $\mathrm{f}$ & $\%$ & \\
\hline $\begin{array}{l}\text { The number of people who give a } \\
\text { like sign and a positive response } \\
\text { describes a sense of trust }\end{array}$ & 20 & 6.7 & 46 & 15.3 & 69 & 23.0 & 83 & 27.7 & 82 & 27.3 & 3.51 \\
\hline $\begin{array}{l}\text { The number of people who gave a } \\
\text { like and a positive response } \\
\text { illustrates that the review is } \\
\text { trustworthy }\end{array}$ & 20 & 6.7 & 38 & 12.7 & 86 & 28.7 & 73 & 24.3 & 83 & 27.7 & 3.54 \\
\hline $\begin{array}{l}\text { The number of people who gave a } \\
\text { like and a positive response } \\
\text { illustrates that the review is liked }\end{array}$ & 11 & 3.7 & 16 & 5.3 & 26 & 8.7 & 90 & 30.0 & 157 & 52.3 & 4.22 \\
\hline
\end{tabular}

The description of several reasons consumers assess the popularity of a post has an average in the range of 3.51 4.22. It illustrated that consumers give varying degrees of agreement when assessing content popularity, but there are also very few considerations. The number of people who gave a like sign and a positive response describing the review as liked is the highest thing to be considered in assessing popularity. Meanwhile, the number of people who gave a like sign and a positive response illustrates that trust is the lowest rating

\section{Usefulness}

Usefulness consists of 3 items that provide characteristics of how consumers evaluate product benefits. A detailed description of each item is described in the following table: 
Table 3. Frequency Distribution of Answers on Usefulness

\begin{tabular}{|c|c|c|c|c|c|c|c|c|c|c|c|}
\hline & \multicolumn{10}{|c|}{ Skor } & \multirow{3}{*}{ Average } \\
\hline & \multicolumn{2}{|l|}{1} & \multicolumn{2}{|l|}{2} & \multicolumn{2}{|l|}{3} & \multicolumn{2}{|l|}{4} & \multicolumn{2}{|l|}{5} & \\
\hline & $\mathrm{f}$ & $\%$ & $\mathrm{f}$ & $\%$ & $\mathrm{f}$ & $\%$ & $\mathrm{~F}$ & $\%$ & $\mathrm{f}$ & $\%$ & \\
\hline $\begin{array}{l}\text { 1. Food reviews post can save time } \\
\text { in decision making }\end{array}$ & 5 & 1.7 & 16 & 5.3 & 21 & 7.0 & 147 & 49.0 & 111 & 37.0 & 4.14 \\
\hline $\begin{array}{l}\text { 2. The existence of food reviews } \\
\text { post is very useful in making } \\
\text { decisions }\end{array}$ & 16 & 5.3 & 12 & 4.0 & 54 & 18.0 & 86 & 28.7 & 132 & 44.0 & 4.02 \\
\hline $\begin{array}{l}\text { 3. The existence of food review } \\
\text { posts is very useful in providing } \\
\text { information on the delicacy of food }\end{array}$ & 5 & 1.7 & 16 & 5.3 & 47 & 15.7 & 105 & 35.0 & 127 & 42.3 & 4.11 \\
\hline
\end{tabular}

The description of several reasons consumers assess the benefits of products has an average in the range of 4.02 4.14 provides an illustration that consumers provide varying degrees of agreement in the sense that there are consumers who use very many considerations in assessing product benefits, but there are also very few considerations. . The existence of posting food reviews can save time in decision making, which is the highest consideration in assessing product benefits. While posting a food review is very useful in decision making is the lowest rating.

\section{Like Intention}

Like intention consists of 3 items that provide characteristics of how consumers intend to give likes to a product. A detailed description of each item is described in the following table:

Table 4. Frequency Distribution of Answers on Like Intention

\begin{tabular}{|c|c|c|c|c|c|c|c|c|c|c|c|}
\hline & \multicolumn{10}{|c|}{ Score } & \multirow{3}{*}{ Average } \\
\hline & \multicolumn{2}{|l|}{1} & \multicolumn{2}{|l|}{2} & \multicolumn{2}{|l|}{3} & \multicolumn{2}{|l|}{4} & \multicolumn{2}{|l|}{5} & \\
\hline & $\mathrm{F}$ & $\%$ & $\mathrm{f}$ & $\%$ & $\mathrm{f}$ & $\%$ & $\mathrm{f}$ & $\%$ & $\mathrm{f}$ & $\%$ & \\
\hline 1. I tend to give a like & 5 & 1.7 & 23 & 7.7 & 43 & 14.3 & 76 & 25.3 & 153 & 51.0 & 4.16 \\
\hline 2. I Hope I give a like & 34 & 11.3 & 37 & 12.3 & 73 & 24.3 & 60 & 20.0 & 96 & 32.0 & 3.49 \\
\hline 3. I intend to give a like & 30 & 10.0 & 22 & 7.3 & 76 & 25.3 & 57 & 19.0 & 115 & 38.3 & 3.68 \\
\hline
\end{tabular}

The description that explains the consumer's desire to give likes for a product on average in the range of 3.49 4.16 gives an illustration that the number of consumers who have the intention or desire to give likes for a product has varying levels. The desire to take an action consists of 3 elements, namely the tendency, hope and intention. Most consumers in realizing the desire are in the stage of a tendency to give a like sign. While the stage of hoping and intending to give a like is a lower response than the stage of the emergence of a tendency.

\section{Share Intention}

Share intention consists of 3 items that provide characteristics of how consumers intend to share a product. A detailed description of each item is described in the following table:

Table 5. Distribution of Response Frequency on Share Intention

\begin{tabular}{|c|c|c|c|c|c|c|c|c|c|c|c|}
\hline & \multicolumn{10}{|c|}{ Score } & \multirow{3}{*}{ Average } \\
\hline & \multicolumn{2}{|l|}{1} & \multicolumn{2}{|l|}{2} & \multicolumn{2}{|l|}{3} & \multicolumn{2}{|l|}{4} & \multicolumn{2}{|l|}{5} & \\
\hline & $\mathrm{f}$ & $\%$ & $\mathrm{f}$ & $\%$ & $\mathrm{f}$ & $\%$ & $\mathrm{f}$ & $\%$ & $\mathrm{f}$ & $\%$ & \\
\hline 1. I intend to share the information & 10 & 3.3 & 11 & 3.7 & 69 & 23.0 & 152 & 50.7 & 58 & 19.3 & 3.79 \\
\hline 2. I plan to share the information & 22 & 7.3 & 16 & 5.3 & 69 & 23.0 & 125 & 41.7 & 68 & 22.7 & 3.67 \\
\hline 3. I hope to share the information & 24 & 8.0 & 21 & 7.0 & 107 & 35.7 & 88 & 29.3 & 60 & 20.0 & 3.46 \\
\hline
\end{tabular}


The description that explains the consumer's desire to share for one product on average in the range of 3.46 3.79 illustrates that the number of consumers who have the intention or desire to share for a product has varying levels. The desire to take an action consists of 3 elements, namely the tendency, hope and intention. Most consumers in realizing the desire are in the stage of a tendency to share products. While the stage of hoping and intending to share is lower in response than the stage of the emergence of a tendency.

\section{SEM-PLS Model}

\section{Measurement Model (Outer Model)}

The PLS model has two parts, namely the measurement model (outer model) and structural model ( inner model) and is processed based on item scores. Testing the measurement model in this research aims to evaluate items that are reflective of their constructs. The analysis of the items used is tested in order to give meaning to the contribution made by the latent variable. Empirical analysis aims to validate the model and construct reliability that reflects the parameters on latent variables or constructs that are built on theory and empirical studies.

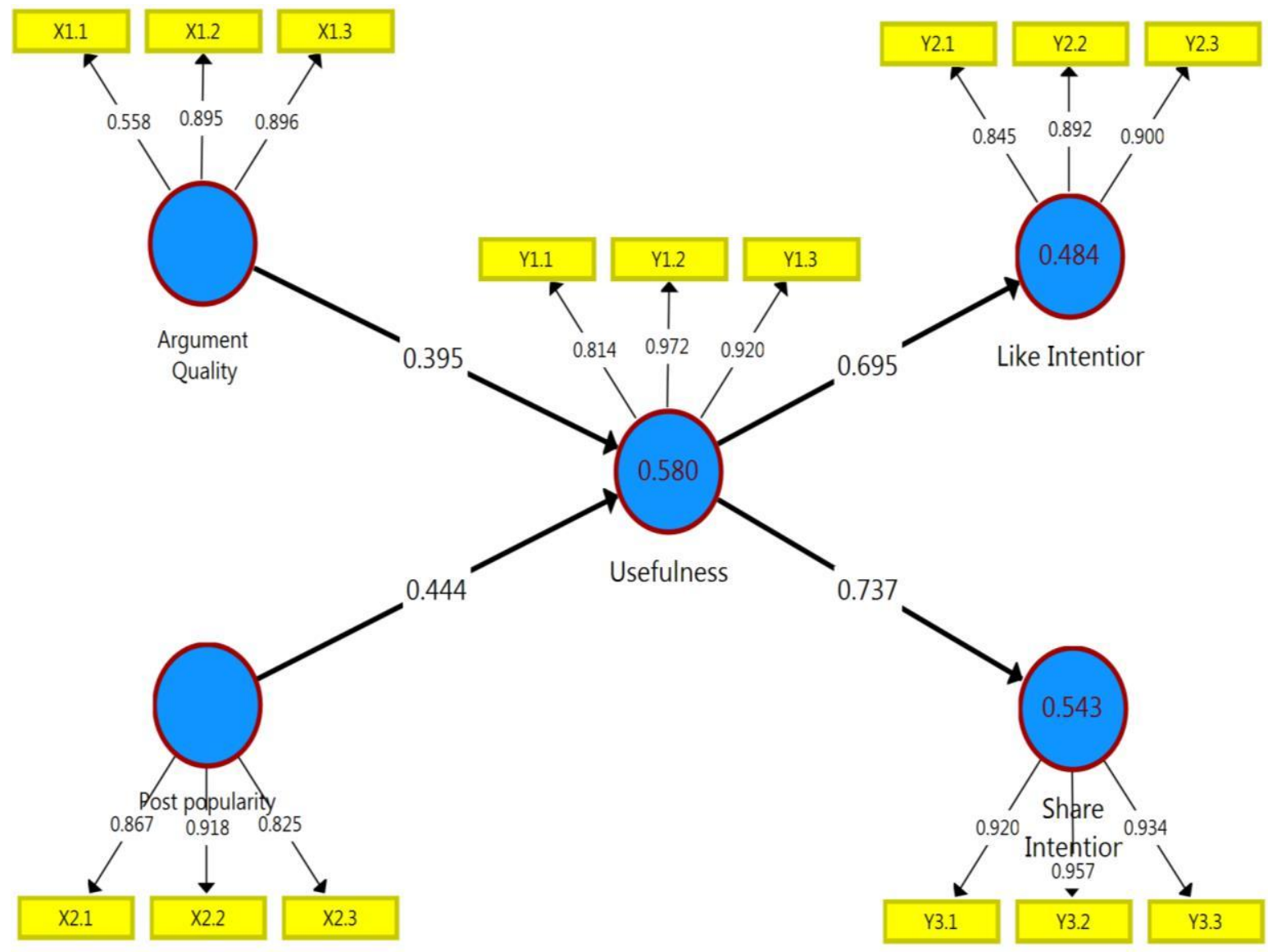

Fig 1. Initial Outer Model

Evaluation of the measurement model with reflective items was analysed by looking at the results of the convergent validity of each item. Convergent validity testing on PLS can be seen from the magnitude of the outer loading of each item on the latent variable. A loading factor of 0.7 or more is considered high enough. 


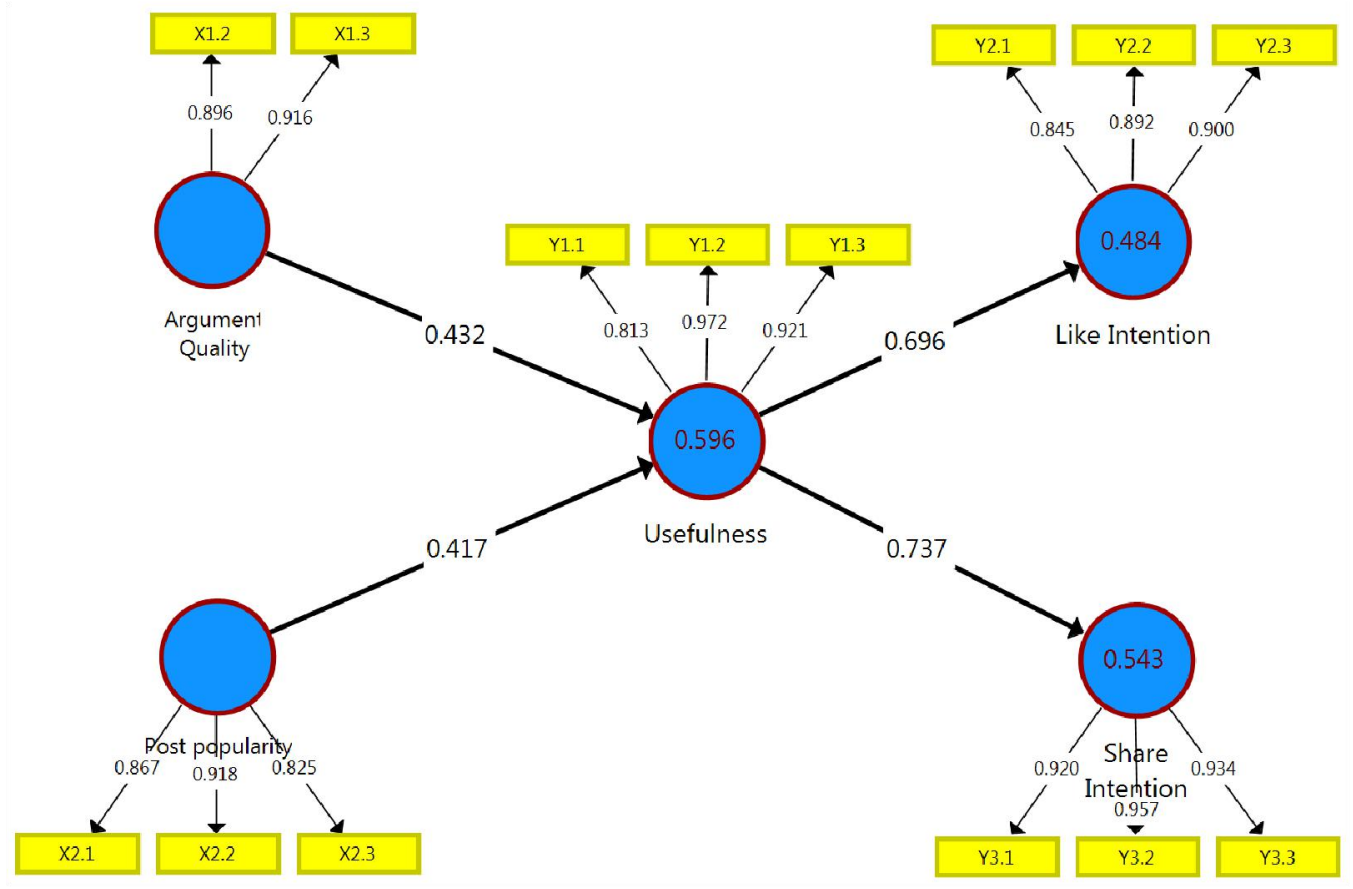

Fig 2. Outer Evaluation Model

The outer model or measurement model is an assessment of the validity and reliability of research variables. The results of the analysis on the initial outer model (Figure 1), one item has a loading factor of less than 0.70 , namely X1.1. Furthermore, the outer model will be evaluated by removing the item (Figure 2). There are three criteria to assess the outer model, namely discriminant validity, composite reliability, and convergent validity. Based on the three assessment criteria of the measurement model, the testing of the measurement model for each item that reflects the construct or latent variable can be explained as follows. The evaluation of the outer model is based on the results of the calculation of the hypothetical model.

\section{a. Discrimination Validity}

Discriminant validity testing in this study uses the value of cross loading and square root of average (AVE) with the aim of checking (testing) whether the item is valid in explaining or reflecting latent variables. Testing the discriminant validity of this research data is presented in Table 6 below.

Table 6. Loading Factor and Crossloading

\begin{tabular}{|l|l|l|l|l|l|}
\hline Items & $\begin{array}{l}\text { Argument } \\
\text { Quality }\end{array}$ & $\begin{array}{l}\text { Post } \\
\text { popularity }\end{array}$ & Usefulness & $\begin{array}{l}\text { Like } \\
\text { Intention }\end{array}$ & $\begin{array}{l}\text { Share } \\
\text { Intention }\end{array}$ \\
\hline X1.2 & $\mathbf{0 . 8 9 6}$ & 0.569 & 0.606 & 0.510 & 0.569 \\
\hline X1.3 & $\mathbf{0 . 9 1 6}$ & 0.614 & 0.669 & 0.577 & 0.613 \\
\hline X2.1 & 0.701 & $\mathbf{0 . 8 6 7}$ & 0.597 & 0.492 & 0.592 \\
\hline X2.2 & 0.576 & $\mathbf{0 . 9 1 8}$ & 0.610 & 0.635 & 0.643 \\
\hline X2.3 & 0.434 & $\mathbf{0 . 8 2 5}$ & 0.618 & 0.497 & 0.619 \\
\hline Y1.1 & 0.452 & 0.553 & $\mathbf{0 . 8 1 3}$ & 0.515 & 0.600 \\
\hline Y1.2 & 0.726 & 0.707 & $\mathbf{0 . 9 7 2}$ & 0.653 & 0.730 \\
\hline Y1.3 & 0.702 & 0.629 & $\mathbf{0 . 9 2 1}$ & 0.704 & 0.664 \\
\hline Y2.1 & 0.433 & 0.432 & 0.597 & $\mathbf{0 . 8 4 5}$ & 0.604 \\
\hline Y2.2 & 0.580 & 0.648 & 0.629 & $\mathbf{0 . 8 9 2}$ & 0.705 \\
\hline Y2.3 & 0.569 & 0.557 & 0.608 & $\mathbf{0 . 9 0 0}$ & 0.667 \\
\hline Y3.1 & 0.537 & 0.658 & 0.693 & 0.686 & $\mathbf{0 . 9 2 0}$ \\
\hline Y3.2 & 0.664 & 0.748 & 0.687 & 0.711 & $\mathbf{0 . 9 5 7}$ \\
\hline
\end{tabular}




\begin{tabular}{|l|l|l|l|l|l|}
\hline Y3.3 & 0.634 & 0.591 & 0.691 & 0.712 & $\mathbf{0 . 9 3 4}$ \\
\hline
\end{tabular}

Validation based on the loading factor on all items is good because it is worth more than 0.7. In addition, all items, apart from having a loading factor of more than 0.70 , also have the highest value in their constructs when compared to crossloading on other constructs. The evaluation of the outer model based on the loading factor and crossloading is included in the good category. Discriminant validity uses square root of average extracted $(\sqrt{\mathrm{AVE}})$. If the value of the root of AVE each latent variable is greater than the correlation with other variables, the instrument said to havediscriminant validity were good as shown in Table 7.Discriminant validity by using the cross loading value. If the cross loading value of each item of the relevant variable is greater than the cross loading value of other variables, then the item is said to be valid. The results of the calculation of discriminant validity using the cross loading value .

Table 7. Discriminant Validity Results

\begin{tabular}{|l|l|l|l|l|l|}
\hline & $\begin{array}{l}\text { Argument } \\
\text { Quality }\end{array}$ & $\begin{array}{l}\text { Like } \\
\text { Intention }\end{array}$ & $\begin{array}{l}\text { Post } \\
\text { popularity }\end{array}$ & $\begin{array}{l}\text { Share } \\
\text { Intention }\end{array}$ & Usefulness \\
\hline Argument Quality & 0.906 & & & & \\
\hline Like Intention & 0.601 & 0.879 & & & \\
\hline Post popularity & 0.654 & 0.623 & 0.871 & & \\
\hline Share Intention & 0.653 & 0.750 & 0.711 & 0.937 & \\
\hline Usefulness & 0.705 & 0.696 & 0.700 & 0.737 & 0.904 \\
\hline
\end{tabular}

Information: The coefficient on the diagonal is the root of AVE; The coefficient outside the diagonal is the correlation coefficient between constructs; AVE $=$ Average Variance Extracted In addition to meeting convergent validity, a reflective measurement model musthave discriminant validity. A measurement model meets discriminant validity if the AVE root of a construct is greater than the correlation coefficient with other constructs. Table 3 explains all the results of discriminatory validity. The results show that the discriminant validity value of a variable is higher than the correlation value between variables. Thus, it can be concluded that the outer model of this research has met discriminant validity.

\section{b. Composite Reliability}

Composite reliability tests the value of reliability between items from the constructs that make it up. The results of composite reliability are said to be good, if the value is above 0.70 . The results of testing the composite reliability of the measurement model can be presented in Table 8 below.

Table 8. Composite Reliability Results

\begin{tabular}{|l|l|l|l|l|}
\hline & $\begin{array}{l}\text { Cronbach's } \\
\text { Alpha }\end{array}$ & $\begin{array}{l}\text { Composite } \\
\text { Reliability }\end{array}$ & $\begin{array}{l}\text { Average } \\
\text { Variance } \\
\text { Extracted } \\
\text { (AVE) }\end{array}$ & Results \\
\hline Argument Quality & 0.783 & 0.902 & 0.821 & Reliable \\
\hline Like Intention & 0.853 & 0.911 & 0.773 & Reliable \\
\hline Post popularity & 0.839 & 0.904 & 0.758 & Reliable \\
\hline Share Intention & 0.930 & 0.956 & 0.878 & Reliable \\
\hline Usefulness & 0.887 & 0.930 & 0.818 & Reliable \\
\hline
\end{tabular}

The reliability test results show that all constructs have a composite reliability coefficient of more than 0.70. Thus, all measurement models used in this study already have high reliability. So that further analysis can be done by examining the goodness of fit model by evaluating the inner model .

\section{c. Convergent Validity}

Convergent validity measures the validity of the item as a construct measure, it can be seen from the outer loading. The outer loading with the highest value means that the item is the strongest / most important measure in reflecting the relevant latent variable. The loading factor value shows the weight of each item as a 
measure of each variable. Items with a large loading factor indicate that the item is a measure of the strongest (dominant) variable. In the PLS model, the loading factor for reflective items is the outer loading .

Table 9. Loading Factor

\begin{tabular}{|c|c|c|c|}
\hline Variable & Items & description & $\begin{array}{l}\text { Loading } \\
\text { Factor }\end{array}$ \\
\hline \multirow{2}{*}{$\begin{array}{l}\text { argument } \\
\text { Quality }\end{array}$} & $\mathrm{X} 1.2$ & Posting food reviews is very useful & 0.896 \\
\hline & $\mathrm{X} 1.3$ & Posting food reviews is very helpful in making decisions & 0.916 \\
\hline \multirow[t]{3}{*}{ Post Popularity } & $\mathrm{X} 2.1$ & $\begin{array}{l}\text { The number of people who give a like sign and a } \\
\text { positive response describes a sense of trust }\end{array}$ & 0.867 \\
\hline & $\mathrm{X} 2.2$ & $\begin{array}{l}\text { The number of people who gave a like and a positive } \\
\text { response illustrates that the review is trustworthy }\end{array}$ & 0.918 \\
\hline & $\mathrm{X} 2.3$ & $\begin{array}{l}\text { The number of people who gave a like and a positive } \\
\text { response illustrates that the review is liked }\end{array}$ & 0.825 \\
\hline \multirow[t]{3}{*}{ Usefulness } & Y1.1 & Posting food reviews can save time in decision making & 0.813 \\
\hline & Y1.2 & $\begin{array}{l}\text { The existence of posting food reviews is very useful in } \\
\text { making decisions }\end{array}$ & 0.972 \\
\hline & Y1.3 & $\begin{array}{l}\text { The existence of food review posts is very useful in } \\
\text { providing information on the delicacy of food }\end{array}$ & 0.921 \\
\hline \multirow[t]{3}{*}{ Like Intention } & Y2.1 & I tend to give a like & 0.845 \\
\hline & Y2.2 & I hope to give a like & 0.892 \\
\hline & Y2.3 & I intend to give a like & 0.900 \\
\hline \multirow[t]{3}{*}{ Share Intention } & Y3.1 & I intend to share the information & 0.920 \\
\hline & Y3.2 & I plan to share the information & 0.957 \\
\hline & Y3.3 & I hope to share the information & 0.934 \\
\hline
\end{tabular}

\section{Model Fit}

Model fit or model fit can be measured by three model fit indices, namely SRMR, model determination $\left(\mathrm{Rm}^{2}\right)$ and the Goodness of Fit (GoF) coefficient. In the SEM model with the Partial Least Square approach or SEM-PLS the level of model fit will use the Standardized Root Mean Square Residual (SRMR) value. SRMR is a fit model developed by $\mathrm{Hu}$ and Bentler (1999) for CB-SEM. SEM-PLS adopted SRMR to determine the difference between the sample covariance and the covariance produced by SEM-PLS. SRMR represents the average value of all standardized residuals, and has a range from 0 to 1 . A model that has a good fit ( good fit) will have an SRMR value of less than 0.08 and a poor fit status if it is more than 0,10 . The model proposed in this study has an SRMR value of 0.110 , which means more than 0.10 , it can be concluded that the model has poor fit status. The NFI value of 0.736 (more than 0.50 ) also explains that the level of model fit is good.

Table 10. Model Fit Test Results with SRMR and NFI

\begin{tabular}{|l|l|l|l|}
\hline Indeks & Statistics & Good Fit Limit & Poor Fit Limit \\
\hline SRMR & 0,110 & Less from 0,08 & More than 0,10 \\
\hline NFI & 0,736 & More than 0,50 & Less from 0,50 \\
\hline
\end{tabular}

The fit of the structural model on the inner model uses the GoF ( goodness of fit ) value to measure how well the resulting model is. The GoF scale has a value range of $0-1$, the closer to 1 , the better the model. A GoF value of more than 0.33 indicates a good model fit. The suitability of other models can be assessed from several calculations such as the coefficient of model determination $\left(\mathrm{R}^{2}\right)$. The coefficient of determination of the model is calculated using all the coefficients of determination $\left(\mathrm{R}^{2}\right)$ in the model. Rated $\mathrm{R}^{2}$ for variable usefulness is 0.596.

This value indicates that the variation in usefulness explained by argument quality and post popularity is 59.6\%, while the rest is explained by other variables . $\mathrm{R}^{2}$ for variables like intention is 0.484 . This value indicates that 
the variation of like intention explained by usefulness is $48.4 \%$, while the rest is explained by other variables. $\mathrm{R}^{2}$ for variable share intention is 0.543 .

This value indicates that the variation in share intention explained by usefulness is $54.3 \%$, while the rest is explained by other variables. Hair et.al (2014) stated that in general the coefficient of determination is low if it is worth 0.20 or less, while in this model the average coefficient of determination is 0.541 (more than 0.20 ).

Table 11. Goodness of Fit (GoF) Index

\begin{tabular}{|l|l|l|}
\hline Variabel & Communality & $\mathrm{R}^{2}$ \\
\hline Argument Quality & 0.821 & \\
\hline Post popularity & 0.758 & \\
\hline Usefulness & 0.818 & 0.596 \\
\hline Like Intention & 0.773 & 0.484 \\
\hline Share Intention & 0.878 & 0.543 \\
\hline Jumlah & 4.048 & 1.623 \\
\hline Rata-rata & 0.810 & 0.541 \\
\hline Indeks (GoF) & 0.662 & \\
\hline
\end{tabular}

Note : The communality value is taken from the AVE . value

The fit of the model can also be calculated using the goodness of fit index. The goodness of fit index $(\mathrm{GoF})$ is defined as the geometric mean or root of the average communality and the average $\mathrm{R}^{2}$ for all endogenous constructs (Tenenhaus et al. 2005). The GoF index shows the predictive power of the overall model. The GoF value has an interval between 0 and 1 . A GoF value that is close to 1, at least 0.33 indicates a good path model estimate (Akter, D'Ambra, and Ray, 2011). The GoF index for this research model is 0.662 . With this, the model structural that explains the relationship the three variables have good predictive power ( fit ).

\section{Structural Model Testing (Inner Model)}

This study uses the SEM PLS model and is processed with SmartPLS version 3.2.7 to evaluate the research model. Hypothesis testing through two stages, namely testing the outer model and testing the inner model. Testing outer models aimed to determine the value of the correlation of latent variables, cross loadings, validity and reliability of the construct and $\mathrm{R}$ Square $\left(\mathrm{R}^{2}\right)$. The test of the inner model aims to determine the path coefficient and inner T-statistic model which shows the level of significance of changes in the independent variable to the dependent variable (Hartono and Abdillah, 2009). Hypothesis testing is based on the results of the analysis of the PLS SEM model which contains all the variables supporting the hypothesis test.

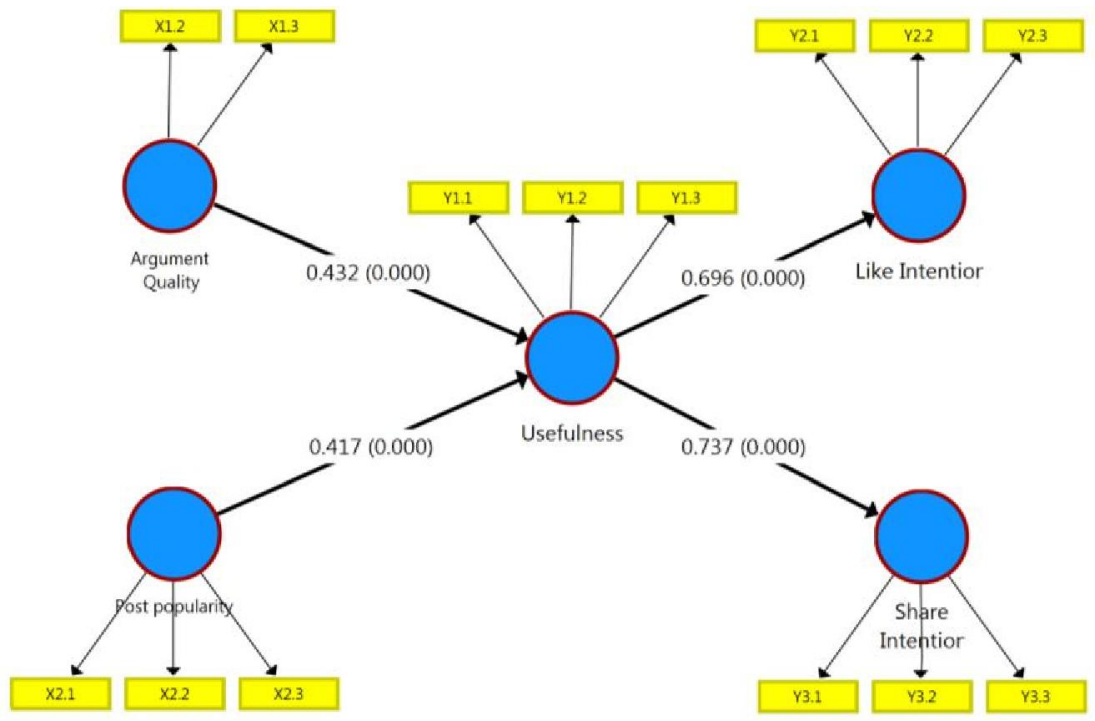

Table 12. Path Coefficient Test Results on Inner Model 


\begin{tabular}{|l|l|l|l|l|}
\hline & $\begin{array}{l}\text { Original } \\
\text { Sample } \\
(\mathrm{O})\end{array}$ & $\begin{array}{l}\text { Standard } \\
\text { Deviation } \\
(\mathrm{STDEV})\end{array}$ & $\begin{array}{l}\mathrm{T} \text { Statistics } \\
(|\mathrm{O} / \mathrm{STDEV}|)\end{array}$ & $\begin{array}{l}\mathrm{P} \\
\text { Values }\end{array}$ \\
\hline $\mathrm{R}^{2}=59.6 \%$ & & & & \\
\hline Argument Quality -> Usefulness & 0.432 & 0.072 & $6,009^{*}$ & 0.000 \\
\hline Post popularity -> Usefulness & 0.417 & 0.067 & $6,203^{*}$ & 0.000 \\
\hline & & & & \\
$\mathrm{R}^{2}=48.4 \%$ & & & & 0.000 \\
\hline Usefulness -> Like Intention & 0.696 & 0.039 & $17,932^{*}$ & \\
\hline & & & & 0.000 \\
\hline $\mathrm{R}^{2}=54.3 \%$ & & & & \\
\hline Usefulness -> Share Intention & 0.737 & 0.037 & $20,070^{*}$ & \\
\hline
\end{tabular}

Information : $\mathrm{ns}=\mathrm{p}>0.05 ; *=\mathrm{p}<0.05$

SmartPLS hypothetical model is calculated using the 3.2.7 version to determine the significance of the existing path coefficients in the model or significance keterdukungan hypothesis (Hartono and Abdillah, 2009; Ghozali, 2008). The path coefficient is significant if $\mathrm{p}$ is less than 0.05 , a summary of the results of the inner model is described in Table 10. The interpretation of the table and figure explains the relationship between variables as follows:

1. Argument quality on usefulness has a coefficient with a positive direction. The calculation results show that the path coefficient of 0.432 with a t-statistic of $6.009(\mathrm{p}=0.000)$ gives the decision that argument quality has a significant effect on usefulness.

2. Post popularity to usefulness has a coefficient with a positive direction. The calculation results show that the path coefficient is 0.417 with a t-statistic of $6.203(\mathrm{p}=0.000)$ giving the decision that post popularity has a significant effect on usefulness.

3. Usefulness to like intention has a coefficient with a positive direction. The calculation results show that the path coefficient is 0.696 with a t-statistic of $17.932(\mathrm{p}=0.000)$ giving the decision that usefulness has a significant effect on like intention.

4. Usefulness on share intention has a coefficient with a positive direction. The calculation results show that the path coefficient of 0.737 with a t-statistic of $20.070(\mathrm{p}=0.000)$ gives the decision that usefulness has a significant effect on share intention.

The modeling in this research argument quality and post popularity on like intention and share intention have an indirect effect through usefulness. The argument quality and post popularity variables in the model are described as having an effect on usefulness first, followed by the direct influence of these variables on like intention and share intention. Table 13 is a summary of the results of the indirect effect test.

Table 13. Results of Indirect Effect

\begin{tabular}{|l|l|l|l|l|}
\hline & $\begin{array}{l}\text { Original } \\
\text { Sample } \\
(\mathrm{O})\end{array}$ & $\begin{array}{l}\text { Standard } \\
\text { Deviation } \\
(\mathrm{STDEV})\end{array}$ & $\begin{array}{l}\mathrm{T} \text { Statistics } \\
(|\mathrm{O} / \mathrm{STDEV}|)\end{array}$ & $\begin{array}{l}\mathrm{P} \\
\text { Values }\end{array}$ \\
\hline $\begin{array}{l}\text { Argument Quality -> Usefulness -> Like } \\
\text { Intention }\end{array}$ & 0.301 & 0.053 & 5.669 & 0.000 \\
\hline $\begin{array}{l}\text { Argument Quality -> Usefulness -> Share } \\
\text { Intention }\end{array}$ & 0.318 & 0.056 & 5.705 & 0.000 \\
\hline $\begin{array}{l}\text { Post popularity -> Usefulness -> Like } \\
\text { Intention }\end{array}$ & 0.290 & 0.051 & 5.685 & 0.000 \\
\hline $\begin{array}{l}\text { Post popularity -> Usefulness -> Share } \\
\text { Intention }\end{array}$ & 0.307 & 0.054 & 5.709 & 0.000 \\
\hline
\end{tabular}

Information : $\mathrm{ns}=\mathrm{p}>0.05 ; *=\mathrm{p}<0.05$ 
The indirect effect on like intention and share intention is the magnitude of the effect obtained from the product of all the paths traversed. The indirect effect of argument quality on like intention through usefulness of $0.301(\mathrm{p}=0.000)$ obtained from the product of $0.432 \times 0.696$ tested significant. The contribution of this high indirect influence is interpreted that high like intention is the effect of high usefulness caused by the formation of good argument quality from consumers. The indirect effect of argument quality on share intention through usefulness of $0.318(\mathrm{p}=0.000)$ obtained from the product of $0.432 \times 0.737$ tested significant. The contribution of this high indirect influence is interpreted that high share intention is the effect of high usefulness caused by the formation of good argument quality from consumers. The indirect effect of post popularity on like intention through usefulness of $0.290(\mathrm{p}=0.000)$ obtained from the product of $0.417 \times 0.696$ tested significant. The contribution of this high indirect influence is interpreted that high like intention is the effect of high usefulness caused by the formation of good post popularity from consumers. The indirect effect of post popularity on share intention through usefulness of $0.307(\mathrm{p}=0.000)$ obtained from the product of 0.417 $\mathrm{x} 0.737$ tested significant. The contribution of this high indirect influence is interpreted that high share intention is the effect of high usefulness caused by the formation of good post popularity from consumers.

Table 14. Results of Direct, Indirect and Total Effects

\begin{tabular}{|l|l|l|l|l|}
\hline Variable relationship Table 14. & $\begin{array}{l}\text { Direct } \\
\text { Influence }\end{array}$ & $\begin{array}{l}\text { Indirect } \\
\text { Influence }\end{array}$ & $\begin{array}{l}\text { Total } \\
\text { Influence }\end{array}$ & $\mathrm{P}$ \\
\hline Argument Quality -> Usefulness & 0.432 & - & 0.432 & 0.000 \\
\hline Post popularity -> Usefulness & 0.417 & - & 0.417 & 0.000 \\
\hline Argument Quality -> Like Intention & - & 0.301 & 0.301 & 0.000 \\
\hline Post popularity -> Like Intention & - & 0.290 & 0.290 & 0.000 \\
\hline Usefulness -> Like Intention & 0.696 & - & 0.696 & 0.000 \\
\hline Argument Quality -> Share Intention & - & 0.318 & 0.318 & 0.000 \\
\hline Post popularity -> Share Intention & - & 0.307 & 0.307 & 0.000 \\
\hline Usefulness -> Share Intention & 0.737 & - & 0.737 & 0.000 \\
\hline
\end{tabular}

Information: $\mathrm{ns}=\mathrm{p}>0.05 ; *=\mathrm{p}<0.05$

On the other hand, the relationship to like and share intention can also be calculated from the total amount of influence which is the result of the sum of direct and indirect effects. The total effect on usefulness is stronger from argument quality, which is 0.432 compared to post popularity. The total effect on the strongest like intention comes from the usefulness effect, which is 0.696 , while the indirect effect is stronger from the argument quality of 0.301 . The total effect on share intention is the strongest sourced from the influence of usefulness, which is 0.737 , while the indirect effect is stronger from argument quality of 0.318 .

\section{Hypothesis Testing Results and Discussion}

In this study there are two hypotheses. Based on the results of the inner model coefficient test, all hypotheses are supported. Furthermore, a detailed explanation of each hypothesis will be presented below.

Hypothesis $\mathbf{H 1}$ states that argument quality has an effect on usefulness. This hypothesis will relate to the results of the argument quality coefficient test on usefulness. The calculation results show that the coefficient of argument quality gives a decision that there is a significant effect on usefulness, so the results of this test explain that $\mathrm{H} 1$ is supported.

Hypothesis $\mathbf{H} 2$ states that post popularity has an effect on usefulness. This hypothesis will relate to the results of the post popularity coefficient test on usefulness. The results of the calculation show that the coefficient of post popularity gives the decision that there is a significant effect on usefulness, so the results of this test explain that $\mathrm{H} 2$ is supported.

Hypothesis $\mathbf{H 3}$ states that argument quality has an effect on like intention through usefulness. This hypothesis will relate to the test results of the indirect effect of argument quality on like 
intention through usefulness. The calculation results show that there is a significant indirect effect of argument quality on like intention through usefulness, so the results of this test explain that $\mathrm{H} 3$ is supported.

Hypothesis $\mathbf{H} 4$ states that post popularity has an effect on like intention through usefulness. This hypothesis will relate to the test results of the indirect effect of post popularity on like intention through usefulness. The results of the calculation show that there is a significant indirect effect of post popularity on like intention through usefulness, so the results of this test explain that $\mathrm{H} 4$ is supported.

Hypothesis $\mathbf{H 5}$ states that argument quality affects share intention through usefulness. This hypothesis will relate to the test results of the indirect effect of argument quality on share intention through usefulness. The calculation results show that there is a significant indirect effect of argument quality on share intention through usefulness, so the results of this test explain that $\mathrm{H} 5$ is supported.

Hypothesis $\mathbf{H 6}$ states that post popularity affects share intention through usefulness. This hypothesis will relate to the test results of the indirect effect of post popularity on share intention through usefulness. The calculation results show that there is a significant indirect effect of post popularity on share intention through usefulness, so the results of this test explain that H6 is supported.

With the emergence of this social media phenomenon, many companies want to adapt to the growing trend. Companies increase business value by increasing customer loyalty, increasing sales and revenue, increasing customer satisfaction, and increasing brand awareness \& customer reputation. When someone provides feedback about a product or service to other people or listeners, or even provides an opportunity to recommend or share experiences with someone, the media presented is in the form of a link. Where they can share the link via social media. Comments or information that someone posted then becomes useful knowledge. Anyone who sees this information will use it. The knowledge gained from social media is believed to be able to effectively reduce the risk or uncertainty of potential customers, thereby enabling comments to influence public perceptions of the company's image. Many comments in the past have claimed that building a good corporate image in the public is a good thing, and vice versa.

\section{REFERENCES}

[1] Ahmed, M.A., \& Zahid Z. (2014). Role of social media marketing to enhance CRM and brand equity in terms of purchase intention. Asian Journal of Management Research, 4(3)

[2] Bhattacherjee, A., \& Premkumar, G. (2004). Understanding changes in belief and attitude toward information technology usage: A theoretical model and longitudinal test. MIS Quarterly, 28(2), 229-254.

[3] Bhattacherjee, A., \& Sanford, C. (2006). Influence processes for information technology acceptance: An elaboration likelihood model. MIS Quarterly, 30(4), 805-825.

[4] Cheung, C.M.K., \& Thadani, D.R. (2012). The impact of electronic word-of-mouth communication: A literature analysis and integrative model. Decision Support Systems, 54(1), 461-470.

[5] Coulter, K.S., \& Punj, G.N. (2004). The effects of cognitive resource requirements, availability, and argument quality on brand attitudes-A melding of elaboration likelihood and cognitive resource matching theories. Journal of Advertising, 33(4), 53-64.

[6] De Vriesa, L., Gensler, S., \& Leeflang, P.S.H. (2012). Popularity of brand posts on brand fan pages: An investigation of the effects of social media marketing. Journal of Interactive Marketing, 26(2), 83-91.

[7] Gautam, V., \& Sharma, V., (2017). The Mediating Role of Customer Relationship on the Social Media Marketing and Purchase Intention Relationship with Special Reference to Luxury Fashion Brands. Journal of Promotion Management, 1-17

[8] Hennig-Thurau, T., Gwinner, K. P., Walsh, G., \& Gremler, D. D. (2004). Electronic Word of Mouth Via Consumer Opinion Platforms: What Motivates Consumers to Articulate Themselves on The Internet?. Journal of Interactive Marketing 18, 38-52.

[9] Hinz, O., Skiera, B., Barrot, C., \& Becker, J.U. (2011). Seeding strategies for viral marketing: An empirical comparison. Journal of Marketing, 75(6), 55-71. 
[10] Hsu, C. -L., \& Lin, J.C. -C. (2008). Acceptance of blog usage: The roles of technology acceptance, social influence and knowledge sharing motivation. Information \& Management, 45(1), 65-74.

[11] Kim, A.J., \& Ko, E. (2012). Do social media marketing activities enhance customer equity? An empirical study of luxury fashion brand. Journal of Business Research, 65(10), 1480-1486.

[12] Sinclair, R.C., Moore, S.E., Mark, M.M., Soldat, A.S., \& Lavis, C.A. (2010). Incidental moods, source likeability, and persuasion: Liking motivates message elaboration in happy people. Cognition and Emotion, 24(6), 940-961. 